\title{
Oxygen Modulates the Glutathione Peroxidase Activity during the L6 Myoblast Early Differentiation Process
}

\author{
Magdalena Hidalgo ${ }^{\mathrm{a}}$ Dominique Marchant ${ }^{\mathrm{a}}$ Patricia Quidu ${ }^{\mathrm{a}}$ Karima Youcef-Ali ${ }^{\mathrm{a}}$ \\ Jean P. Richalet ${ }^{\mathrm{a}}$ Michele Beaudry ${ }^{\mathrm{a}}$ Sophie Besse $\mathrm{B}^{\mathrm{b}, \mathrm{c}}$ Thierry Launay $\mathrm{M}^{\mathrm{a}, \mathrm{b}}$ \\ aParis Cité Sorbonne, Université Paris 13, EA 2363 Réponses Cellulaires et Fonctionnelles à l'Hypoxie, \\ bParis Cité Sorbonne, Université Paris Descartes, Paris, INSERM U902, France
}

\section{Key Words}

Myoblast differentiation • Oxygen • Oxidative stress $\cdot$ Akt $•$ Glutathione peroxidase

\begin{abstract}
Aim: This work aims to study the regulation of the glutathione peroxidase and catalase activities in myoblasts from the $\mathrm{L} 6$ line exposed to $21 \%, 5 \%$ and $1 \% \mathrm{O}_{2}$ during the cell differentiation. Material and Methods: Rat L6 myoblasts were grown in 1\%, $5 \%$ or $21 \% \mathrm{O}_{2}$ in the presence or absence of $\mathrm{N}$-acetyl cysteine. The cell proliferation was evaluated by determining the doubling time and kinetics of cultures by counting cells. The cell differentiation was analyzed by determining the myogenic fusion index using antibodies against the myosin heavy chain. The glutathione peroxidase and catalase activities were assayed. The p110-PI3K/Thr308-Akt pathway was studied using western blotting. The oxidative status of the cells was carried out by determining TBARS. Results: $5 \% \mathrm{O}_{2}$ improves the glutathione peroxidase activity, p110-PI3K/Thr308-Akt pathway and differentiation while $1 \% \mathrm{O}_{2}$ alters all these parameters compared to $21 \% \mathrm{O}_{2}$. NAC $(0.5 \mathrm{mM})$ can prevent the deleterious effects of hypoxia $\left(1 \% \mathrm{O}_{2}\right)$ on the L6 myoblast proliferation and enhances the myoblast differentiation when exposed to $21 \% \mathrm{O}_{2}$. TBARS are reduced in $5 \% \mathrm{O}_{2}$ compared to both $21 \%$ and $1 \% \mathrm{O}_{2}$. Conclusion: The glutathione peroxidase activity and p110-PI3K/Thr308-Akt are both modulated in the same way by oxygen.
\end{abstract}




\section{Introduction}

During one's life, skeletal muscles are submitted to mechanical loads inducing micro traumas. In order to repair these lesions, skeletal muscles possess a remarkable feat of regeneration, comparable to embryonic myogenesis. Their regeneration depends on the activation of specific cells called satellite cells [1]. These mononuclear, quiescent and undifferentiated cells are located between the lamina basal and the sarcolemma of muscle fibers. The satellite cells are myogenic precursors originated in the somitic mesoderm of the embryo [2]. When activated, most of these cells are subjected to a process of differentiation depending on the expression of the myogenic factors such as MyoD, Myf5, myogenin and MRF4 while a minority undergoes self-renewal and returns to a quiescent state based on the expression of the genetic marker PAX7 [3], resulting in the formation of new muscle fibers. The terminal differentiation has been shown to be modulated by several signaling pathways such as Notch, calcineurin, p38-MAPK, and PI3K/Akt/mTOR [4-7].

Skeletal muscle loss happens in several environmental or pathological conditions such as altitude hypoxia [8], heart deficiency [9] and periphery arterial diseases [10]. All these observations suggest a relationship between atrophy and low $\mathrm{O}_{2}$ availability. Since atrophied and weakened muscles contribute to the morbidity and mortality of patients, many studies have been conducted in the last decade to better understand the role of oxygen in the activation of the satellite cells. The results of these studies should be of great interest for the prevention of muscle atrophy and the improvement of cell transplantation.

In mice, in vitro culture experiments have showed that under $3 \% \mathrm{O}_{2}$, the myoblast differentiation is impaired $[11,12]$ and at $1 \% \mathrm{O}_{2}$ both the proliferation and differentiation are inhibited. The differential effects of hypoxia by species can be observed; in a previous work we showed that in rat myoblast from the L6 line, the proliferation and differentiation slow down at $1 \% \mathrm{O}_{2}$ exposure [13]. Below $1 \% \mathrm{O}_{2}$, the mouse myoblast differentiation is blocked in a Notch-dependent manner by activating Notch-responsive promoters and increasing the expression of direct downstream genes [4]. On the other hand, low oxygen levels block the PI3K/Akt pathway in an HIF-1 independent fashion [7]. Similarly, hypoxia $\left(1 \% \mathrm{O}_{2}\right)$ suppresses the IGF-induced Akt-mTOR and p38-MAPK activities [14]. Conversely, at 3\% $\mathrm{O}_{2}$ hypoxia activates the phosphorylation of Akt and improves the primary myoblasts differentiation in the rat [15]. The same results were observed in bovine primary myoblasts exposed to $1 \% \mathrm{O}_{2}$ and murine myoblasts from the $\mathrm{C} 2 \mathrm{C} 12$ line exposed to $6 \% \mathrm{O}_{2}$. At $6 \% \mathrm{O}_{2}$, intracellular reactive oxygen species [12] production was lower than the one in $20 \%$ ambient $\mathrm{O}_{2}$ [16]. The oxidative intracellular environment appears to be an important differentiation factor depending on the ambient $\mathrm{O}_{2}$ level. Interestingly, the role of ROS as a regulator of the IGF-1/Akt pathway was proposed in rat cultured dermal fibroblasts [17]. In normal fibroblasts, IGF-1 induced a strong phosphorylation of Akt whereas phosphorylation is attenuated in fibroblasts expressing the phenotypic characteristics of diabetes, inflammation or hypercortisolemia [17]. This work proposes to study whether oxygen at hyperoxic $\left(21 \% \mathrm{O}_{2}\right)$, physiological $\left(5 \% \mathrm{O}_{2}\right)$ and hypoxic $\left(1 \% \mathrm{O}_{2}\right)$ levels can regulate the L6 myoblast differentiation by modulating the activity of two important enzymes involved in the detoxification of ROS such as glutathione peroxidase and catalase.

\section{Materials and Methods}

L6 myoblasts culture, ambient oxygen

To eliminate the heterogeneous responses that could result from using primary cultures, rat myoblasts from the L6 line have been chosen. The L6 myoblasts were grown in DMEM supplemented with $4 \mathrm{mM}$ L-glutamine, $1 \mathrm{mM}$ sodium pyruvate and 10\% FBS (GM). The differentiation medium [18] was obtained by DMEM medium supplemented with $4 \mathrm{mM}$ L-glutamine, $1 \mathrm{mM}$ sodium pyruvate and 2\% FBS.

Oxygen levels were obtained using a chamber in which ambient air was flushed out by $95 \% \mathrm{~N}_{2} /$ $5 \% \mathrm{CO}_{2}$ until the required percentages of oxygen were obtained (1\% or $\left.5 \%\right)$. The percentages of oxygen 
Hidalgo et al.: Oxygen Glutathione Peroxidase the L6 Differentiation

were controlled using an $\mathrm{O}_{2}$ analyzer (QS System, Rendsburg, Germany). In all the experiments, the culture media were incubated at least 12 hours at $1 \%$ and $5 \% \mathrm{O}_{2}$ before being used for culture. The chambers were pre-warmed at $37^{\circ} \mathrm{C}$ prior to culture. The cells were incubated in hypoxia chambers in a humidified atmosphere. The cells grown at $21 \% \mathrm{O}_{2}$ in the ambient air were directly placed in a $5 \% \mathrm{CO}_{2}$ incubator at $37^{\circ} \mathrm{C}$ in a humidified atmosphere.

\section{Cell proliferation}

The L6 myoblasts were seeded at $50 \times 10^{3}$ cells per well in 6-well plates. Kinetics were obtained by removing the cells after $48 \mathrm{~h}$ and $72 \mathrm{~h}$ of culture using trypsin. The cells were incubated in trypan blue and non-colored viable cells were counted in a Malassez cell. Before counting, we checked that all the cells were removed from the plates. The doubling time was calculated as $\mathrm{t}=48 /((\ln y / \mathrm{x}) \ln 2)$ where $\mathrm{y}$ is the number of cells after culture and $x$ the number of seeded cells after 48h [19]. The data presented are the results of six different cultures.

\section{Cell differentiation}

Two protocols of differentiation were performed in this work. We observed that when the cells were seeded at $50 \times 10^{3}$ per well in 6-well plates and $50 \times 10^{4}$ in $100 \mathrm{~mm}$ diameter Petri-dishes and were incubated at different oxygen environments. $80-90 \%$ confluence was achieved at $72 \mathrm{~h}$ at $21 \% \mathrm{O}_{2}$. In the first protocol (P1), called "spontaneous differentiation", the cells differentiated spontaneously in a growth medium (GM). In this protocol, first myotubes appeared at day 5 of the culture and we let the differentiation continue until day 8. In the second protocol (P2), called "induced differentiation", all the cells were cultured for $72 \mathrm{~h}$ in $\mathrm{GM}$ to $21 \% \mathrm{O}_{2}$ in order to eliminate the effects of oxygen on the proliferation and focus on the process of differentiation only. The L6 myoblasts were then incubated in DM at $21 \%, 5 \%$ or $1 \% \mathrm{O}_{2}$. All the data presented are the result of six different cultures.

\section{Fusion index and immunostaining}

Fusion indexes (number of nuclei in myotubes/total number of nuclei) were calculated for both "spontaneous" and "induced" protocols, by day 8 for P1 and day 3 in DM for P2. At these times, the cells were fixed in $100 \%$ methanol at $-20^{\circ} \mathrm{C}$. They were incubated in $0.05 \%$ Triton- $100 \mathrm{X}$ for $10 \mathrm{~min}$ and blocked in $3 \%$ BSA. The cultures were then incubated with a primary antibody against fast MHC (MY-32, Sigma, 1:400). After being washed, the cells were incubated with an anti-mouse FITC conjugated (Z0420, Dako, France) or a Hrp conjugated (F0232, Dako France) antibody. The nuclei were stained with Hoechst H33258 (Sigma, France 1:1000) or hematoxylin (Sigma, France). The sections were washed and mounted in Immunomount (Thermo Electron Corporation, France).

\section{Western blot}

The Akt pathway was analyzed during the P2 protocol. The L6 myoblasts were removed after $24 \mathrm{~h}$ and $48 \mathrm{~h}$ of culture in DM and were homogenized and sonicated in a lysis buffer $(50 \mathrm{mM}$ Tris $\mathrm{HCl}, 100 \mathrm{mM} \mathrm{NaCl}$, pH 7.5, $2 \mathrm{mM}$ EDTA, $2 \mathrm{mM}$ EGTA, $50 \mathrm{mM} \beta$-glycerophosphate, $50 \mathrm{mM}$ sodium fluoride, $1 \mathrm{mM} \mathrm{Na}_{3} \mathrm{VO}_{4}, 120$ nM okadaic acid, $1 \mathrm{mM}$ PMSF, $1 \%$ Triton-100X supplemented with protease inhibitors). Homogenates were centrifuged at $1000 \mathrm{~g}$ for $10 \mathrm{~min}$ at $4^{\circ} \mathrm{C}$. Protein samples, separated by $12 \%$ SDS-PAGE, were transferred to nitrocellulose membranes (Hybond) as described by Towbin et al [20]. The membranes were blocked with $5 \%$ skimmed milk powder and incubated with the following primary antibodies: anti- $\alpha$-tubulin (T0926, Sigma), anti-phospho-Akt Thr308 (244F9, Cell Signaling, France) and anti-p110-PI3K (4255, Cell Signaling, France). After being washed they were incubated with the appropriate secondary antibodies: anti-rabbit HRP conjugated (111-036-045, Jackson ImmunoResearch), anti-mouse HRP conjugated (115-036-062, Jackson ImmunoResearch) and detected by chemiluminescence. All the experiments were repeated at least three times. For quantification, blots were exposed to X-ray films during intervals of different lengths and the films were scanned and analyzed using NIH ImageJ software.

\section{Insulin treatment}

For this experiment the P2 protocol was chosen in order to focus on the effect of oxygen on the activation of the differentiation process by insulin. $50 \times 10^{4}$ cells were seeded in Petri-dishes of $100 \mathrm{~mm}$ diameter and cultured in GM for $72 \mathrm{~h}$ at $21 \% \mathrm{O}_{2}$. The cultures were then incubated in hypoxic chambers at 
Hidalgo et al.: Oxygen Glutathione Peroxidase the L6 Differentiation

$1 \%, 5 \%, 21 \% \mathrm{O}_{2}$ with or without $100 \mathrm{mM}$ insulin (Sigma, France). The incubation times were 4 hours for the analysis of the Akt pathway stimulation and 3 days for the evaluation of the fusion index.

\section{Determination of total glutathione peroxidase activity and catalase activity}

The L6 myoblasts were seeded at $50 \times 10^{3}$ cells per well in 6-well plates and were incubated in GM for 5 days at $1 \%, 5 \%$ and $21 \% \mathrm{O}_{2}$. The onset of the differentiation was verified by microscopy. The protein extraction was carried out by lysing and sonication in a $0.5 \mathrm{mM}$ Tris buffer, $10 \mathrm{mM}$ DTPA, $100 \mathrm{mM}$ phenyl methyl sulfonyl fluoride (PMSF). Whole cell homogenates were obtained by centrifugation at $10000 \mathrm{~g}$, in order to analyze the glutathione peroxidase, catalase activities and the TBARS quantification. The data presented are the result of three different cultures.

The catalase activity was quantified using the method described by Beers and Sizer [21]. Briefly, 20 $\mu \mathrm{l}$ of cell homogenates were incubated with $880 \mu \mathrm{l}$ of phosphate buffer $\left(50 \mathrm{mM} \mathrm{KH}_{2} \mathrm{PO}_{4}, 50 \mathrm{mM} \mathrm{Na} \mathrm{HPO}_{4}\right.$ ) and $100 \mu \mathrm{l}$ of $0.15 \% \mathrm{H}_{2} \mathrm{O}_{2}$. The kinetics of the disappearance of $\mathrm{H}_{2} \mathrm{O}_{2}$ was followed at $240 \mathrm{~nm}$ for $1 \mathrm{~min}$. The catalase activity was calculated as follows:

Ucat/gprotein $=(((\triangle O D / \mathrm{min}) X R V) /(0,0436 \mathrm{XSV}) / \mathrm{m})$

where $\mathrm{RV}=$ reaction volume, $\mathrm{SV}=$ sampling volume and $\mathrm{m}=$ muscle cell mass in $\mathrm{g}$.

The glutathione peroxidase activity was assayed on cell homogenates using the glutathione peroxidase assay kit (CGP1, Sigma, France) as described by the manufacturer's protocol. Briefly, $50 \mu$ l of cell homogenates were incubated with tert-butylhydroperoxide (t-BHP), NADPH, and the assay buffer containing glutathione and glutathione reductase for $1 \mathrm{~min}$. The reaction was monitored at $340 \mathrm{~nm}$ for $3 \mathrm{~min}$. The activity was calculated as follows:

$m U G P x / m l=(((\Delta O D / \mathrm{min}-\triangle O D b l a n k / \mathrm{min}) X R V) / 6,22 X S V) X 2 X 1000$ where $\mathrm{RV}=$ reaction volume and $\mathrm{SV}=$ sample volume.

The TBARS analysis was performed in cells cultured at $1 \%, 5 \%, 21 \% \mathrm{O}_{2}$ and in the culture medium. The lipid peroxidation was monitored by measuring the TBARS formed with minor modifications [22]. Briefly, $450 \mu \mathrm{l}$ of shredded muscle cells were added to $100 \mathrm{l}$ of sodium dodecyl sulfate (SDS), $750 \mu \mathrm{l}$ of $10 \%$ acetic acid, $750 \mu \mathrm{l}$ of $1 \%$ thiobarbituric acid, agitated and incubated for $1 \mathrm{~h}$ at $95^{\circ} \mathrm{C}$. The precipitates were extracted in $3 \mathrm{ml}$ of butanol and centrifuged for $10 \mathrm{~min}$ at $10000 \mathrm{~g}$. The absorption was read at $532 \mathrm{~nm}$. To quantify the TBARS in homogenates, the absorptions were compared with those obtained with a range of concentrations of maldhehyde acid (MDA).

\section{$N$-acetyl cysteine treatment}

The P1 protocol was used in this experiment. The L6 myoblasts were seeded at $50 \times 10^{3}$ cells per well of 6 well-plates and incubated in GM at $21 \%$ or $1 \% \mathrm{O}_{2}$. NAC was added at day 0 (seeding), and every subsequent $48 \mathrm{~h}$ at concentration 0.5 to $5 \mathrm{mM}$ when the culture medium was renewed. Previously, a doseresponse of NAC was performed. The deleterious effects of NAC on both the proliferation and differentiation were observed between $5 \mathrm{mM}$ and $1.5 \mathrm{mM}$. After $72 \mathrm{~h}$ of culture, the cells were counted as described above. After 8 days, the cells were immunostained using anti-MHC antibodies to identify myotubes.

\section{Statistical analyses}

The statistical significance of data is presented as mean \pm SD. The Effects of oxygen on the proliferation, fusion indexes and oxidative stress parameters were evaluated using the two-parameter test of analysis of variance (2D-anova). The Newman Keuls test was used for post hoc testing. All statistical analyses were carried out using Statistica software (StartSoft Inc. Tulsa, UK, USA), in all statistical testing 0.05 was considered to indicate statistical significance.

\section{Results}

L6 myoblast proliferation is altered in $1 \% \mathrm{O}_{2}$

To study the effects of hypoxia on cell proliferation, the L6 myoblasts were cultured in $\mathrm{GM}$ and exposed to $1 \%, 5 \%$ and $21 \% \mathrm{O}_{2}$. Control cultures were exposed to $21 \% \mathrm{O}_{2}$ and 
Fig. 1. L6 lineage myoblasts were cultured at different percentages of oxygen in GM for $72 \mathrm{~h}$ in order to evaluate the effects of oxygen on the proliferation process. The cells were removed and counted each $24 \mathrm{~h}$ to follow the kinetics of growth (A). Generation time was calculated for each percentage of oxygen using the relation $\mathrm{t}=\mathrm{y} /((\ln y / \mathrm{x}) \ln 2)$ where $\mathrm{y}$ is the number of cells after $48 \mathrm{~h}$ of culture and $\mathrm{x}$ the number of seeded cells (B). Data are presented as mean $\pm S D, * \mathrm{p} \leq 0.05$, *** $\mathrm{p} \leq 0.001$.

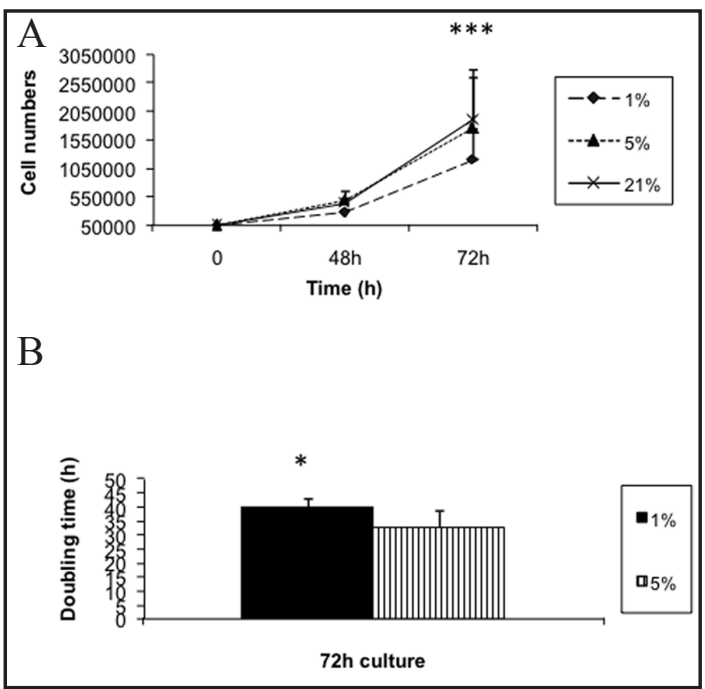

$5 \% \mathrm{O}_{2}$ corresponding to in vitro and in vivo normoxia conditions respectively. Cells cultured in hypoxia were exposed to $1 \% \mathrm{O}_{2}$ corresponding to pathological hypoxia. The number of viable cells in culture dishes was assessed every 24 hours for 3 days. Figure $1 \mathrm{~A}$ shows that after $48 \mathrm{~h}$ and $72 \mathrm{~h}$ of culture, the number of cells was lower at $1 \% \mathrm{O}_{2}$, compared to $21 \%$ and $5 \% \mathrm{O}_{2}$. In addition, no difference was observed between $21 \%$ and $5 \% \mathrm{O}_{2}$. The generation time was calculated and results show an increase of 8 hours at $1 \% \mathrm{O}_{2}$ compared to other conditions (Fig. 1B). These results suggest that the L6 myoblasts proliferation was slower when the myoblasts were grown in hypoxia compared to control conditions. It has to be noted that the same results were obtained using Cyquant Assay Kit (Invitrogen,france) (Data not shown).

L6 myoblast differentiation depends on the $\mathrm{O}_{2}$ concentration in the culture chamber

The muscle differentiation is characterized by the myoblast fusion yielding the formation of plurinucleated myotubes. To analyze the effects of oxygen on this process, L6 myoblasts were cultured following two protocols P1 and P2. Differentiated myotubes were detected with an anti-MHC antibody and nuclei were stained with Hoechst at day 8 in GM for P1 and at day 3 in DM for P2. Figure 2A-C shows the differentiation in the different $\mathrm{O}_{2}$ conditions during the $\mathrm{P} 2$ protocol. We can notice that the size of myotubes was bigger at $5 \% \mathrm{O}_{2}$ and the number of nuclei per myotube was higher (Fig. 2A-C). Then, the fusion index (number of nuclei per myotubes/total number of nuclei in the culture) was calculated to quantify the cell differentiation. In Figure 2D, the fusion index was significantly higher after 10 days of culture at $5 \% \mathrm{O}_{2}(35 \%)$ compared to $21 \% \mathrm{O}_{2}(27 \%)$. In the $1 \% \mathrm{O}_{2}$ condition, the fusion index was drastically reduced (2\%) compared to $5 \%$ and $21 \% \mathrm{O}_{2}$ and few myotubes were detected by immunohistochemistry (Fig. 2A). To validate these data, myoblasts were cultured for 8 days in DM to induce cell differentiation (P2). Similar results were obtained (Fig. 2E).

Altogether, these data show that the differentiation is more effective at $5 \% \mathrm{O}_{2}$ and altered by hypoxia.

\section{PI3K/Akt pathway is modulated in an oxygen-dependent manner}

The PI3K/Akt/mTOR signaling pathway has been shown to regulate the myoblast differentiation [23-25]. The state of activation of this pathway was analyzed at $1 \%, 5 \%$, $21 \% \mathrm{O}_{2}$ by Western blotting using antibodies against the p110 catalytic subunit of PI3K and the phosphorylated form of Thr308-Akt. Figure 3A shows that the level of the p110-PI3K protein was significantly higher in $5 \% \mathrm{O}_{2}$-cultured cells compared to $21 \% \mathrm{O}_{2}$ after $48 \mathrm{~h}$ of culture. Interestingly, the level of p110-PI3K protein was lower at $1 \% \mathrm{O}_{2}$ compared to cells cultivated at $5 \% \mathrm{O}_{2}$, after $24 \mathrm{~h}$ and $48 \mathrm{~h}$ of culture. Consistent with this result, the protein 


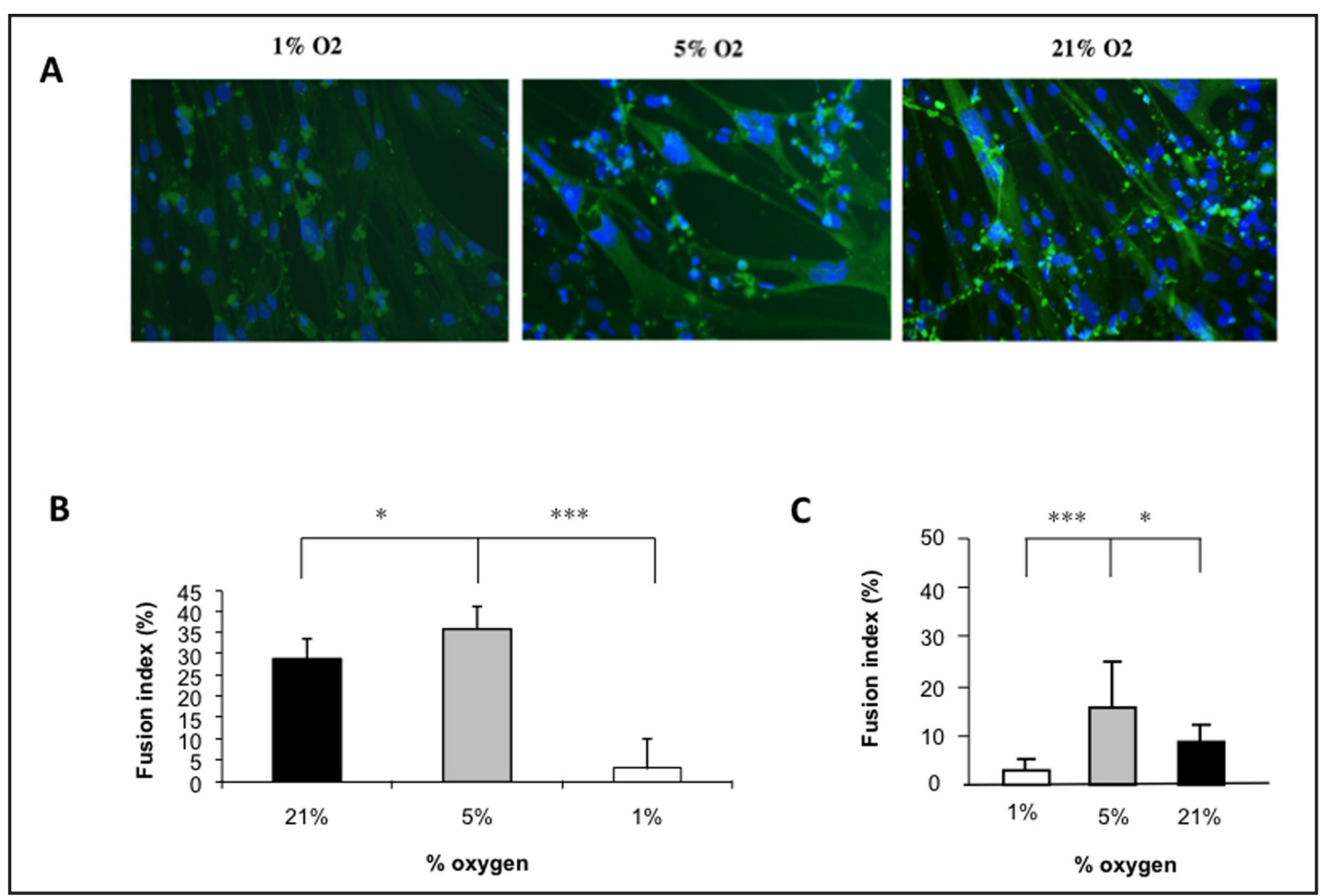

Fig. 2. In order to evaluate the effects of oxygen on differentiation we measured the fusion index after the "P1 protocol" where L6 myoblasts were grown 8 days in GM (C) or the "P2 protocol" where L6 myoblasts were cultured $72 \mathrm{~h}$ in GM and 3 days in DM (A-B). For both protocols myotubes were stained with antibody against fast $\mathrm{MHC}$ that recognizes all myotubes. In figure $\mathrm{B}$ and $\mathrm{C}$ we can notice that the fusion index is improved at $5 \% \mathrm{O}_{2}$ while it is altered at $1 \%$ compared to $21 \% \mathrm{O}_{2}$. Data are presented as mean $\pm \mathrm{SD},{ }^{*} \mathrm{p} \leq 0.05$, $* * * \mathrm{p} \leq 0.001$.

level of Thr308-Akt was also weaker in $1 \% \mathrm{O}_{2}$-cultured cells compared to $5 \%$ and $21 \% \mathrm{O}_{2}$ after $48 \mathrm{~h}$ of culture (Fig. 3B). Altogether, these results suggest that the low oxygen level (1\%) inhibits the activation of the PI3K/Akt signaling pathway in the L6 myoblasts whereas it is up-regulated at $5 \% \mathrm{O}_{2}$ compared to $21 \% \mathrm{O}_{2}$.

The binding of insulin to its receptor activates the phosphorylation of Insulin Receptor Substrates (IRS) and the PI3K pathway. Therefore, the effects of insulin on the L6 myoblast differentiation were studied in each oxygen condition. Figure 3C shows that insulin treatment stimulates the phosphorylation level of Thr308-Akt protein in L6 myoblasts grown in 5\% and $21 \% \mathrm{O}_{2}$ but not in $1 \% \mathrm{O}_{2}$. In addition, the fusion indexes were measured in myoblasts cultured with and without insulin (Fig. 3D). In agreement with our previous results the fusion indexes were significantly higher in insulin-treated cells compared to the control cells at $5 \%$ and $21 \% \mathrm{O}_{2}$. However, the fusion indexes were not different in the cells treated or not with insulin at $1 \% \mathrm{O}_{2}$.

These results show that the insulin treatment did not activate the PI3K/Akt signaling pathway or restore the myoblast differentiation process in hypoxia.

Glutathione peroxidase activities are dependent on oxygen in culture medium

Mitochondria have long been considered as likely sites for oxygen sensing, and the electron transport chain acts as an $\mathrm{O}_{2}$ sensor by releasing Reactive Oxygen Species [12]. In response to hypoxia, these could accumulate and alter the differentiation process. To analyze this parameter in both the hypoxic and normoxic L6 myoblasts, the cells were allowed to grow in GM for 5 days. At this time, the Glutathione peroxidase (GPx), catalase activity and TBAR accumulation were estimated. Figure 4A shows that the TBAR accumulation was weaker in the L6 cells incubated at $5 \% \mathrm{O}_{2}$ compared to $21 \%$ and $1 \% \mathrm{O}_{2}$. Interestingly, the 


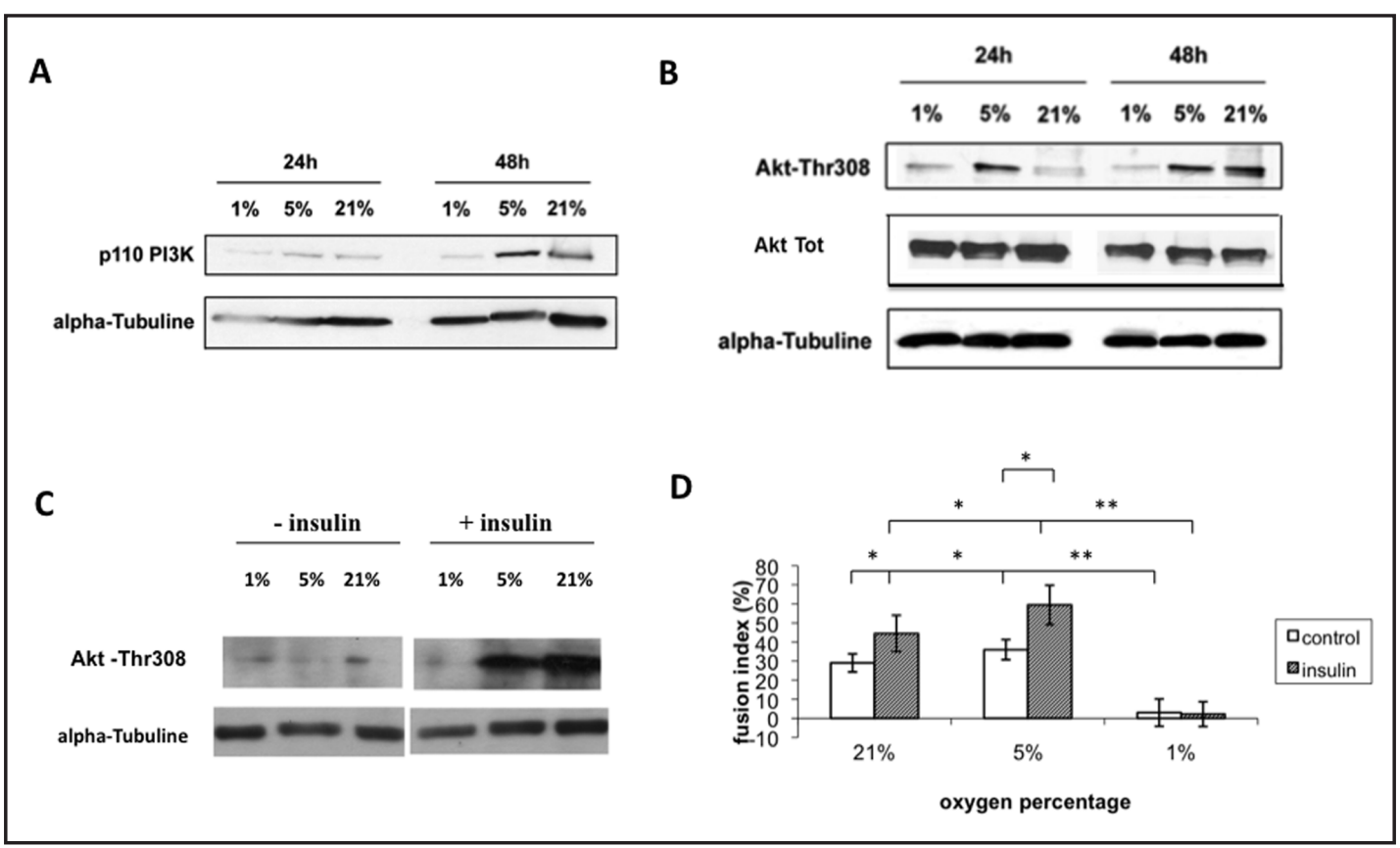

Fig. 3. In these experiments, we aimed to evaluate the role PI3K/Thr308-Akt in the differentiation process. In order to eliminate the effect of oxygen on proliferation we first incubated L6 myoblasts 72h in GM at $21 \% \mathrm{O}_{2}$ and then differentiation was induced by incubation in DM for $24 \mathrm{~h}$ and $48 \mathrm{~h}$ at the three percentages of oxygen in A, B, C and D. In C and D, insulin (100 mM) was added at the time of incubation in DM at the different percentages of oxygen for 4 hours (C) and for 3 days (D). (C) Evaluation of Thr308-Akt after 4 hours of insulin stimulation by western blotting at $1 \%, 5 \%$ and $21 \% \mathrm{O}_{2}$. Presented gels are representative of at least three independent experiments. (D) Quantification of fusion indexes after 3 days in DM at different percentages of oxygen in presence or absence of insulin. Data are presented as mean $\pm \mathrm{SD}, * \mathrm{p} \leq 0.05$, ** $\mathrm{p} \leq 0.001$.
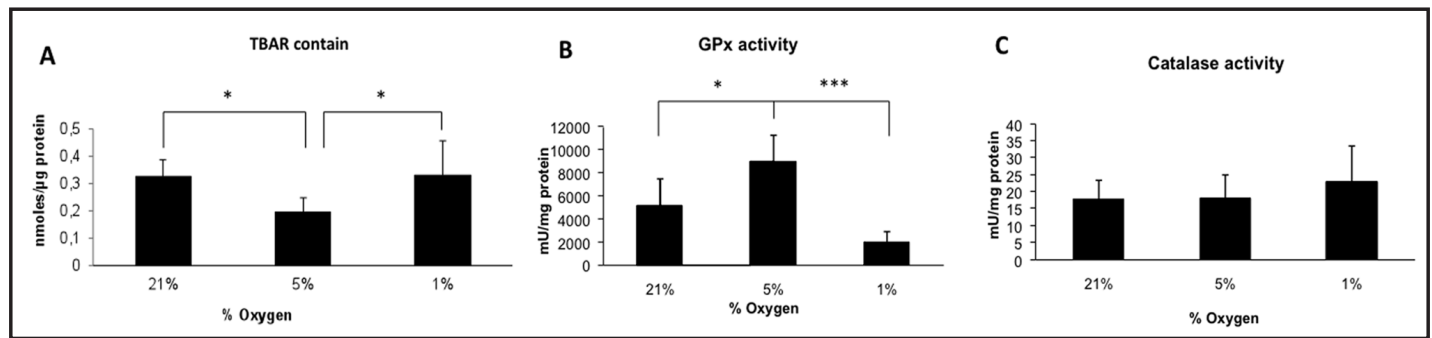

Fig. 4. The oxidative status was measured during differentiation to evaluate its role at the onset of spontaneous differentiation. For this purpose, cells were grown in GM for 5 days and the TBARS cell contain (A), catalase activity (B) and glutathione peroxidase (C) were quantified at different $\mathrm{O}_{2}$ percentages. At this day of culture, we observed the formation of the first myotubes at $21 \%$ and $5 \% \mathrm{O}_{2}$. Data are presented as mean $\pm \mathrm{SD},{ }^{*} \mathrm{p} \leq 0.05,{ }^{* * *} \mathrm{p} \leq 0.001$.

accumulation of TBARS was not significantly different between $21 \%$ and $1 \% \mathrm{O}_{2}$. Figure $4 \mathrm{~B}$ shows that the GPx activity was significantly weaker in cells cultivated at $1 \% \mathrm{O}_{2}$ compared to cells cultivated at $21 \%$ and $5 \% \mathrm{O}_{2}$. In agreement with the TBARS quantification, the GPx activity was higher in the $5 \% \mathrm{O}_{2}$-cultivated cells compared to the $21 \% \mathrm{O}_{2}$-cultivated cells (Fig. 4B). Figure 4C shows no significant differences between the different $\mathrm{O}_{2}$ conditions for the catalase activity.

Altogether, these results suggest that $21 \% \mathrm{O}_{2}$ induces an oxidative stress in L6 myoblasts and consequently, $5 \% \mathrm{O}_{2}$ seems to be the optimal condition for cell differentiation. Moreover, an 


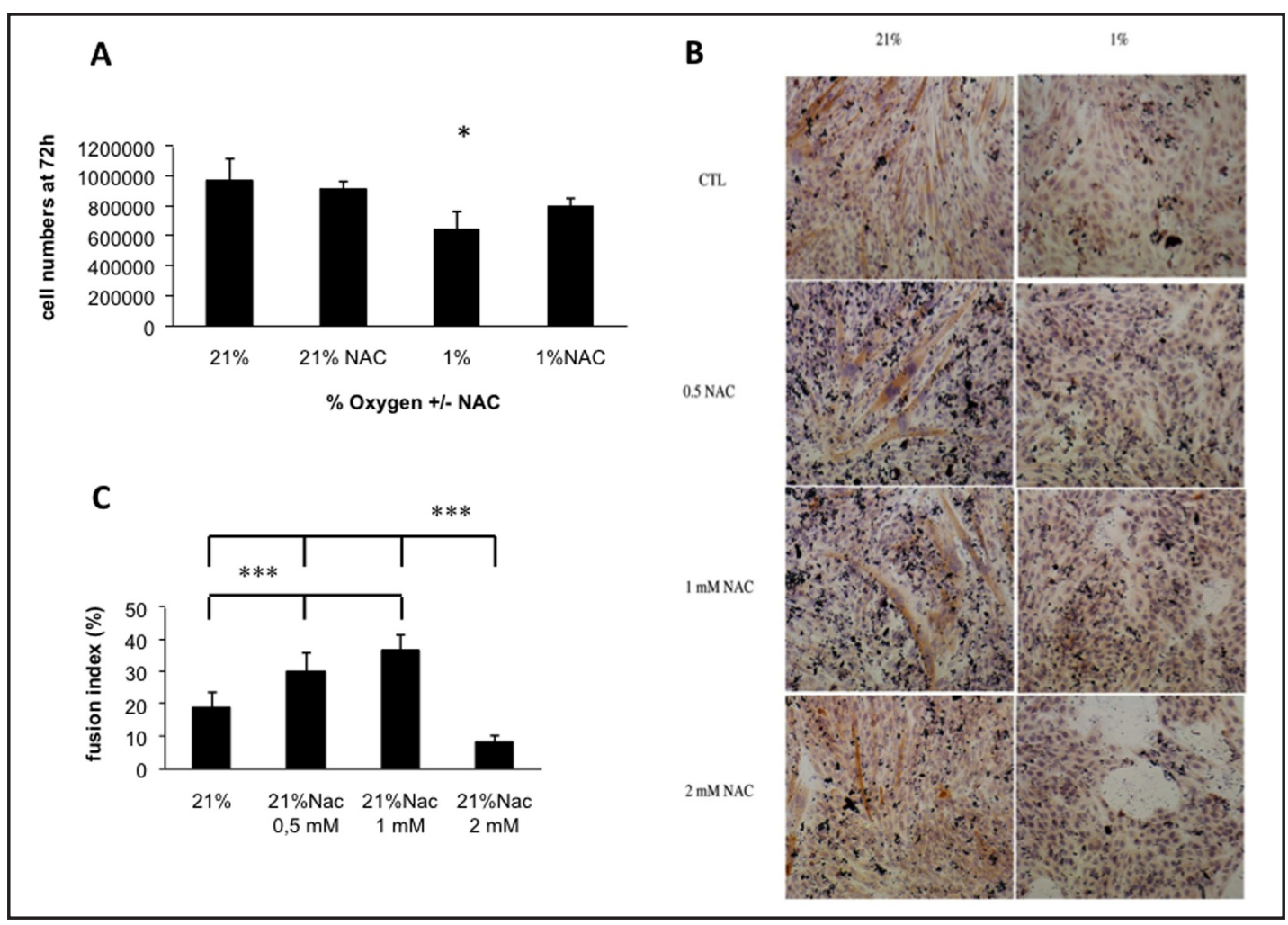

Fig. 5. NAC which is known to reduce the production of ROS was added to culture media at concentrations ranging from 0.5 to $5 \mathrm{mM}$ every $48 \mathrm{~h}$. (A) Counting of cells after 3 days of cultures. (B) Immunostaining using an anti-fast MHC antibody at day 8. CTL: control culture without NAC. (C) Quantification of fusion indexes. Data are presented as mean $\pm \mathrm{SD}, * \mathrm{p} \leq 0.05$. ${ }^{* * *} \mathrm{p} \leq 0.001$.

increase in the TBARS quantity is correlated with a weaker GPx activity in hypoxic cells. In the same way, the increase in GPx activity was correlated with a weaker TBARS accumulation in the normoxic cells $\left(5 \% \mathrm{O}_{2}\right)$.

$\mathrm{N}$-acetyl cysteine counteracts the alteration of myoblast proliferation at $1 \% \mathrm{O}_{2}$

The consumption of NAC antioxidant has been recommended to increase the level of GPx and control the ROS production. In order to known whether the control of the ROS production could improve the L6 proliferation in hypoxia $\left(1 \% \mathrm{O}_{2}\right), \mathrm{NAC}$ was added to the medium at T0 and after $48 \mathrm{~h}$ of culture. Dose responses of NAC were carried out and the number of cells was estimated. Between $1 \mathrm{mM}$ and $5 \mathrm{mM}$, the NAC treatment induced a decrease in the cell proliferation at both $21 \%$ and $1 \% \mathrm{O}_{2}$ conditions compared to the untreated L6 cells (data not shown). However, Figure $5 \mathrm{~A}$ shows that $0.5 \mathrm{mM}$ NAC did not improve the number of cells after $72 \mathrm{~h}$ of culture at $21 \% \mathrm{O}_{2}$ but this dose was sufficient to increase the number of cells cultivated at $1 \% \mathrm{O}_{2}$ compared to the untreated cells at $1 \% \mathrm{O}_{2}$.

These results show that the NAC treatment can counteract the decrease in cell proliferation in myoblasts exposed to severe hypoxia.

NAC improves the differentiation process at $21 \% \mathrm{O}_{2}$ but does not counteract the deleterious effect of $1 \% \mathrm{O}_{2}$ conditions

As an accumulation of TBARS at both $21 \%$ and $1 \% \mathrm{O}_{2}$ was observed in cultured myoblasts, it was suggested that NAC could improve the differentiation process in these oxygen conditions. As observed in myoblast proliferation experiments, the NAC treatment $(\geq 1 \mathrm{mM})$ had deleterious effects on both spontaneous and induced differentiation processes at $1 \%$ and $21 \% \mathrm{O}_{2}$ (data not shown). Figure $5 \mathrm{~B}-\mathrm{C}$ shows the cell differentiation in $1 \%$ and 
$21 \% \mathrm{O}_{2}$ with several concentrations of NAC. When added at $0.5 \mathrm{mM}$ or $1 \mathrm{mM}$, NAC improved the cell differentiation at $21 \% \mathrm{O}_{2}$ after 10 days in GM. Unfortunately, these concentrations did not improve the cell differentiation process in $1 \% \mathrm{O}_{2}$-cultured cells (Fig. 5B). Altogether, these results show that the NAC treatment cannot counteract the decrease in cell differentiation in severe hypoxia.

\section{Discussion}

The objective of this work was to highlight the role of Akt and oxidative stress in the regulation of the differentiation process of myoblasts from the L6 line by ambient oxygen. Our main results identified $5 \% \mathrm{O}_{2}$ as an optimal oxygen level for a reducing environment improving the PI3K/Akt activation. This results in the enhanced myoblast differentiation process. At $1 \% \mathrm{O}_{2}$, the Gpx activity and Thr308-Akt phosphorylation were altered resulting in the accumulation of TBARS and the alteration of the myoblast differentiation process.

In the 2000's, oxygen has been suggested to be an important regulator of myogenesis. Most studies have focused on the effects of hypoxia on myoblast differentiation and controversial results were obtained. Actually, Chakravarthy et al. [15] showed that low oxygen (3\%) enhanced in vitro potential of satellite cells while Di Carlo et al. [12] observed a deleterious effect of hypoxia (1\%) on both the proliferation and differentiation of C2C12 mouse myoblasts. The main explanation for this discrepancy could be the findings of Becker et al [18] and Brevetti et al [26] who measured the $\mathrm{pO}_{2}$ in different skeletal muscles. They found that the intracellular normoxia within skeletal muscles was between $3 \%$ and $8 \% \mathrm{O}_{2}$. This could explain Chakravarthy's results [15]. In agreement with these findings, we show, in this work, an improvement of the differentiation process at $5 \% \mathrm{O}_{2}$ while it is altered at $1 \% \mathrm{O}_{2}$. Our results are not entirely consistent with those of Chakravarthy et al. [15]. These authors showed an enhancement of cell-forming colonies on rat primary satellite cell culture at $3 \% \mathrm{O}_{2}$ while no improvement was observed using myoblasts from the L6 line, when incubated at $5 \% \mathrm{O}_{2}$. This discrepancy begs different responses to the oxygen availability for cells comprised in primary satellite cell cultures contrary to what it has been described before [27].

In this report, we show an $\mathrm{O}_{2}$-dependent regulation of the p110-PI3K/Thr308-Akt pathway during the differentiation of $\mathrm{L} 6$ myoblasts. Compared to $21 \% \mathrm{O}_{2}$, phosphorylation of Thr308-Akt is improved at $5 \% \mathrm{O}_{2}$ but altered at $1 \% \mathrm{O}_{2}$. This regulation results in the improvement of the L6 myoblast fusion at $5 \% \mathrm{O}_{2}$ and the alteration of the fusion at $1 \% \mathrm{O}_{2}$ compared to $21 \% \mathrm{O}_{2}$ conditions. The insulin incubation which is known to phosphorylate Thr308-Akt [28] and to improve the muscle differentiation [29] could not counteract the deleterious effect of $1 \% \mathrm{O}_{2}$ on the myoblast differentiation. Moreover, our results showed an alteration of the Thr308-Akt phosphorylation, suggesting a loss of sensitivity of the Akt pathway to insulin. Insulin and IGF-1 share the same signaling pathway at the IRS1 level [30]. Majmundar et al [7] found a loss of sensitivity of the IGF- 1 receptor at $0.5 \% \mathrm{O}_{2}$ in C2C12 cells. Such a loss of sensitivity has been correlated with an accumulation of ROS in cultured fibroblasts from diabetic rats [17]. In our study, cultured L6 myoblasts at both $21 \%$ and $1 \%$ $\mathrm{O}_{2}$ exhibit a higher TBAR accumulation compared to $5 \% \mathrm{O}_{2}$. Moreover, the accumulation is accompanied by an alteration of the glutathione peroxidase activity only at $1 \% \mathrm{O}_{2}$. On the other hand, at $5 \% \mathrm{O}_{2}$ the level of TBAR is low while the GPx activity is high. In L6 myoblasts $5 \% \mathrm{O}_{2}$ seems to be the optimal condition for the best balance between the TBARS production and detoxification. At $1 \% \mathrm{O}_{2}$ we can suggest that the oxidative stress is very high and the low activity of GPx does not allow the removing of ROS, which bind to cellular molecules such as IRS and alter the differentiation [17]. At $21 \% \mathrm{O}_{2}$ the high production of TBARS is detoxified by glutathione peroxidase, which allows the differentiation to occur. This hypothesis is strengthened by the action of NAC on the differentiation. In fact, NAC at low concentrations $(0.5 \mathrm{mM}$ and $1 \mathrm{mM})$ can improves the differentiation at $21 \% \mathrm{O}_{2}$ while it does not restore the differentiation at $1 \% \mathrm{O}_{2}$. Interestingly, we found similar fusion indexes in cultures at 
Hidalgo et al.: Oxygen Glutathione Peroxidase the L6 Differentiation

$5 \% \mathrm{O}_{2}$ and $21 \% \mathrm{O}_{2}$ in the presence of $0.5 \mathrm{mM} \mathrm{NAC} \mathrm{(data} \mathrm{not} \mathrm{shown).} \mathrm{However,} \mathrm{it} \mathrm{should} \mathrm{be}$ noted that the differentiation was completely inhibited at a concentration of NAC over $1 \mathrm{mM}$ whatever the level of oxygen. Similar results were observed on the proliferation where NAC has no effect at $0.5 \mathrm{mM}$ and inhibits cell proliferation at concentrations greater than $0.5 \mathrm{mM}$. Unexpectedly, $0.5 \mathrm{mM} \mathrm{NAC}$ could restore growth at $1 \% \mathrm{O}_{2}$. While these findings are consistent with Hansen et al [16] who found that a reducing environment enhances the myogenesis in satellite cells of aged muscles, they indicates that antioxidants during myogenesis must be used cautiously. This may explain why Won et al [31] who used 5 mM NAC observed an inhibition of the differentiation.

While the data obtained at $21 \% \mathrm{O}_{2}$ and $5 \% \mathrm{O}_{2}$ clearly show that the Akt pathway is an oxygen-dependant regulator of the myoblasts differentiation mediated by ROS, as described by Bitar et al [17] in fibroblasts, the low level of oxygen (1\%) seems to interfere with many others pathways. Thus, it would be useful to carry out further research on the interaction between Insulin receptors, IRS and ROS by using a combinations of NAC and Insulin or IGF1. Moreover, calcium homeostasis could be another factor involved in the myoblast differentiation.

In conclusion, ourstudyshows thatoxygen is a keyregulator of the myoblastdifferentiation mediated by the oxidative status and Akt. The balance between the TBARS production and the detoxification is very important to induce the Thr308-Akt phosphorylation and the differentiation program. Recently, technics have been performed to improve the survival of engrafted cells in both skeletal [32] and cardiac muscles [33] by preconditioning cells at low oxygen levels or with antioxidants [34]. Our study shows that further research should be done to assess the combination of these two technics for the preparation of myoblasts. In addition, the low oxygen levels and the high activity of the ROS detoxification enzymes seem to be of great interest to maintain adult myogenesis and muscle mass.

\section{References}

1 Mauro A: Satellite cell of skeletal muscle fibers. J Biophys Biochem Cytol 1961;9:493-495.

- Hawke TJ, Garry DJ: Myogenic satellite cells: Physiology to molecular biology. J Appl Physiol 2001;91:534551.

3 Kuang S, Gillespie MA, Rudnicki MA: Niche regulation of muscle satellite cell self-renewal and differentiation. Cell Stem Cell 2008;2:22-31.

4 Gustafsson MV, Zheng X, Pereira T, Gradin K, Jin S, Lundkvist J, Ruas JL, Poellinger L, Lendahl U, Bondesson M: Hypoxia requires notch signaling to maintain the undifferentiated cell state. Dev Cell 2005;9:617-628.

5 Friday BB, Mitchell PO, Kegley KM, Pavlath GK: Calcineurin initiates skeletal muscle differentiation by activating mef2 and myod. Differentiation 2003;71:217-227.

6 Cuenda A, Cohen P: Stress-activated protein kinase-2/p38 and a rapamycin-sensitive pathway are required for c2c12 myogenesis. J Biol Chem 1999;274:4341-4346.

7 Majmundar AJ, Skuli N, Mesquita RC, Kim MN, Yodh AG, Nguyen-McCarty M, Simon MC: O regulates skeletal muscle progenitor differentiation through phosphatidylinositol 3-kinase/akt signaling. Mol Cell Biol 2012;32:36-49.

-8 Howald H, Hoppeler H: Performing at extreme altitude: Muscle cellular and subcellular adaptations. Eur J Appl Physiol 2003;90:360-364.

-9 Callahan DM, Toth MJ: Skeletal muscle protein metabolism in human heart failure. Curr Opin Clin Nutr Metab Care 2013;16:66-71.

10 Partovi S, Schulte AC, Aschwanden M, Staub D, Benz D, Imfeld S, Jacobi B, Broz P, Jager KA, Takes M, Huegli RW, Bilecen D, Walker UA: Impaired skeletal muscle microcirculation in systemic sclerosis. Arthritis Res Ther 2012;14:R209.

11 Yun Z, Lin Q Giaccia AJ: Adaptive myogenesis under hypoxia. Mol Cell Biol 2005;25:3040-3055.

12 Di Carlo A, De Mori R, Martelli F, Pompilio G, Capogrossi MC, Germani A: Hypoxia inhibits myogenic differentiation through accelerated myod degradation. J Biol Chem 2004;279:16332-16338. 
Hidalgo et al.: Oxygen Glutathione Peroxidase the L6 Differentiation

13 Launay T, Hagstrom L, Lottin-Divoux S, Marchant D, Quidu P, Favret F, Duvallet A, Darribere T, Richalet JP, Beaudry M: Blunting effect of hypoxia on the proliferation and differentiation of human primary and rat 16 myoblasts is not counteracted by epo. Cell Prolif 2010;43:1-8.

14 Ren H, Accili D, Duan C: Hypoxia converts the myogenic action of insulin-like growth factors into mitogenic action by differentially regulating multiple signaling pathways. Proc Natl Acad Sci U S A 2010;107:58575862.

15 Chakravarthy MV, Spangenburg EE, Booth FW: Culture in low levels of oxygen enhances in vitro proliferation potential of satellite cells from old skeletal muscles. Cell Mol Life Sci 2001;58:1150-1158.

16 Hansen JM, Klass M, Harris C, Csete M: A reducing redox environment promotes c2c12 myogenesis: Implications for regeneration in aged muscle. Cell Biol Int 2007;31:546-553.

17 Bitar MS, Al-Mulla F: Ros constitute a convergence nexus in the development of igf1 resistance and impaired wound healing in a rat model of type 2 diabetes. Dis Model Mech 2012;5:375-388.

-18 Becker A, Stadler P, Lavey RS, Hansgen G, Kuhnt T, Lautenschlager C, Feldmann HJ, Molls M, Dunst J: Severe anemia is associated with poor tumor oxygenation in head and neck squamous cell carcinomas. Int J Radiat Oncol Biol Phys 2000;46:459-466.

19 Kitzmann M, Bonnieu A, Duret C, Vernus B, Barro M, Laoudj-Chenivesse D, Verdi JM, Carnac G: Inhibition of notch signaling induces myotube hypertrophy by recruiting a subpopulation of reserve cells. J Cell Physiol 2006;208:538-548.

20 Towbin H, Staehelin T, Gordon J: Electrophoretic transfer of proteins from polyacrylamide gels to nitrocellulose sheets: Procedure and some applications. Proc Natl Acad Sci U S A 1979;76:4350-4354.

21 Beers RF, Jr., Sizer IW: A spectrophotometric method for measuring the breakdown of hydrogen peroxide by catalase. J Biol Chem 1952;195:133-140.

-22 Ohkawa H, Ohishi N, Yagi K: Assay for lipid peroxides in animal tissues by thiobarbituric acid reaction. Anal Biochem 1979;95:351-358.

23 Bodine SC, Stitt TN, Gonzalez M, Kline WO, Stover GL, Bauerlein R, Zlotchenko E, Scrimgeour A, Lawrence JC, Glass DJ, Yancopoulos GD: Akt/mtor pathway is a crucial regulator of skeletal muscle hypertrophy and can prevent muscle atrophy in vivo. Nat Cell Biol 2001;3:1014-1019.

24 Wilson EM, Rotwein P: Selective control of skeletal muscle differentiation by akt1. J Biol Chem 2007;282:5106-5110.

25 Wu M, Falasca M, Blough ER: Akt/protein kinase b in skeletal muscle physiology and pathology. J Cell Physiol 2011;226:29-36.

26 Brevetti LS, Chang DS, Tang GL, Sarkar R, Messina LM: Overexpression of endothelial nitric oxide synthase increases skeletal muscle blood flow and oxygenation in severe rat hind limb ischemia. J Vasc Surg 2003;38:820-826.

27 Urbani L, Piccoli M, Franzin C, Pozzobon M, De Coppi P: Hypoxia increases mouse satellite cell clone proliferation maintaining both in vitro and in vivo heterogeneity and myogenic potential. PLoS One 2012; 7:e49860.

-28 Feng XT, Wang TZ, Leng J, Chen Y, Liu JB, Liu Y, Wang WJ: Palmitate contributes to insulin resistance through downregulation of the src-mediated phosphorylation of akt in c2c12 myotubes. Biosci Biotechnol Biochem 2012;76:1356-1361.

29 Mikula M, Dzwonek A, Hennig EE, Ostrowski J: Increased mitochondrial gene expression during 16 cell myogenesis is accelerated by insulin. Int J Biochem Cell Biol 2005;37:1815-1828.

-30 Taniguchi CM, Emanuelli B, Kahn CR: Critical nodes in signalling pathways: Insights into insulin action. Nat Rev Mol Cell Biol 2006;7:85-96.

31 Won H, Lim S, Jang M, Kim Y, Rashid MA, Jyothi KR, Dashdorj A, Kang I, Ha J, Kim SS: Peroxiredoxin-2 upregulated by nf-kappab attenuates oxidative stress during the differentiation of muscle-derived c2c12 cells. Antioxid Redox Signal 2012;16:245-261.

-32 Liu W, Wen Y, Bi P, Lai X, Liu XS, Liu X, Kuang S: Hypoxia promotes satellite cell self-renewal and enhances the efficiency of myoblast transplantation. Development 2012;139:2857-2865.

-33 Hu X, Yu SP, Fraser JL, Lu Z, Ogle ME, Wang JA, Wei L: Transplantation of hypoxia-preconditioned mesenchymal stem cells improves infarcted heart function via enhanced survival of implanted cells and angiogenesis. J Thorac Cardiovasc Surg 2008;135:799-808.

34 Drowley L, Okada M, Beckman S, Vella J, Keller B, Tobita K, Huard J: Cellular antioxidant levels influence muscle stem cell therapy. Mol Ther 2010;18:1865-1873. 